\title{
INDUÇÃO IN VITRO DA GERMINAÇÃO DE SEMENTES DE Oncidium flexuosum (ORCHIDACEAE) POR FUNGOS MICORRÍZICOS RIZOCTONIÓIDES ${ }^{(\mathbf{1})}$
}

\author{
Olinto Liparini Pereira(2), Maria Catarina Megumi Kasuya(3), \\ Christtianno de Lima Rollemberg ${ }^{(4)} \&$ Arnaldo Chaer Borges ${ }^{(5)}$
}

\begin{abstract}
RESUMO
A germi nação de sementes e o desenvolvimento de protocórmios de Onci dium flexuosum (Orchidaceae) induzidos simbioticamente são descritos pela primeira vez. As sementes de $\mathbf{O}$. flexuosum foram inoculadas com dez fungos micorrízicos rizoctonióides, previamente isolados de micorrizas de dez espécies de orquídeas neotropicais do Brasil, incluindo 0 . flexuosum. Foram utilizados um isolado pertencente à espécie Epulorhiza repens, dois pertencentes à E pulorhiza epi phytica, seis de Ceratorhiza spp. e um de Rhizoctonia sp. Sementes inoculadas com o isolado M2 de Ceratorhiza sp., originalmente isolado do sistema radicular de 0 . flexuosum em habitat natural, promoveu a germinação das sementes em sete dias e em, aproximadamente, $\mathbf{3 0}$ \% das plântulas, houve formação de fol has após $\mathbf{5 0}$ dias de incubação, apresentando pelotons em algumas células do protocórmio e das radicelas. Os demais isolados promoveram a germinação das sementes; entretanto, não promoveram um desenvolvimento ótimo dos protocórmios. Sementes incubadas na ausência de fungos micorrízicos não germinaram. A especificidade e a alta dependência de 0 . flexuosum pela associação micorrízica ficaram claras. Aspectos relativos à especificidade, anatomia da interação fungo-planta e a importância da seleção de estirpes fúngicas, previamente ao uso de fungos micorrízicos para o cultivo si mbiótico a partir de sementes de 0 . flexuosum são discutidos.
\end{abstract}

Termos de indexação: conservação de orquídeas, ecologia mi crobiana, interação planta-microrganismo, micologia, Ceratorhiza, Epulorhiza, Rhizoctonia.

\footnotetext{
(1) Trabalho desenvol vido no L aboratório de Associações Micorrízicas, I nstituto de Biotecnol ogia A plicada à Agropecuária, BI OAGRO Departamento de Microbiologia, Universidade Federal de Viçosa - UFV. Recebido para publicação em março de 2004 e aprovado em dezembro de 2004

(2) Mestre em Microbiologia Agrícola, BI OAGRO, Universidade Federal deViçosa - UFV. Departamento de Microbiologia, CEP 36570000 Viçosa (MG). Bolsista CNPq. E-mail: liparini@bol.com.br

(3) Professora Adjunto do Departamento de Microbiologia, UFV. Bolsista CNPq. E-mail: mkasuya@ufv.br

(4) Bolsista Iniciação Científica PIBIC/CNPq. E-mail: christthroll@yahoo.com

(5) Professor Titular do Departamento de Microbiologia, UFV. E-mail: chaer@ufv.br
} 


\begin{abstract}
SUMMARY: IN VITRO SYMBIOTIC SEED GERMINATION OF Oncidium flexuosum (Orchidaceae) BY RHIZOCTONIA-LIKE MYCORRHIZAL FUNGI
\end{abstract}

\begin{abstract}
Symbi otic in vitro seed germination and protocorm devel opment of Oncidium flexuosum is described for the first time. $\mathrm{O}$. flexuosum seeds were inoculated with ten mycorrhizal isolates, ori gi nal ly obtai ned from themycorrhiza of ten neotropical Brazilian orchid species, including $\mathrm{O}$. flexuosum. One of thei solates bel ongs to E pul orhiza repens, two to E pul orhiza epiphytica, six to Ceratorhiza spp., and one to Rhizoctonia sp. Seeds inoculated with the M2 isolate of Ceratorhiza sp., origi nally isolated from theroot system of wild O. flexuosum, promoted seed germination within 7 days and about $30 \%$ of the seedl ings produced leaves after 50 days of incubation, all of which presented pelotons in some protocorm and rhizoid cells. Theother isol ates stimulated seed germination, al though they did not lead to an ideal protocorm development. Seeds incubated in the absence of the mycorrhizal fungi failed to germinate. The degree of specificity and dependence of $\mathrm{O}$. flexuosum from mycorrhizal fungi thus was evident. Aspects of the specificity, anatomy of the plant-fungus interaction and the importance of the fungal strain selection prior to the use of mycorrhizal fungi for the symbiotical $\mathrm{O}$. flexuosum cultivation from seds are discussed.
\end{abstract}

Index terms: orchid conservation, microbial ecology, plant-microorganism interaction, mycol ogy, Ceratorhiza, Epulorhiza, Rhizoctonia.

\section{NTRODUÇÃO}

As espécies pertencentes à família Orchidaceae: terrestres, epífitas ou rupícolas, associam-se com fungos micorrízicos para favor ecer a germinação de sementes e o estabel ecimento do protocórmi o em seu ambiente natural (Arditti, 1992; Andersen \& Rasmussen, 1996; Peterson et al., 1998; Zettler, 1997; Pereira et al., 2003b). As orquídeas utilizam-se da digestão de massas de hifas formadas intracelularmente (pelotons), principalmente nas células do córtex da raiz, como fonte de energia durante o estádio heterotrófico do seu ciclo de vida (Harvais \& Hadl ey, 1967; Smith \& Read, 1997; Peterson et al., 1998). Essefenômeno, conhedidopor micoheterotrofismo, não é exclusivo da família Orchidaceae, sendo também relatado em outras famílias demonocotiledôneas, a saber: Burmanniaceae, Corsiaceae, Lacandoniaceae, Petrosaviaceae e Triuridaceae e em famílias de dicotiledôneas, como: Ericaceae (Monotropoideae), Polygalaceae e Gentianaceae (Leake, 1994; McK endrick et al., 2000; Read et al., 2000; Taylor et al., 2002).

Diversos métodos e meios de cultura são relatados para o cultivo assimbiótico de sementes de orquídeas in vitro (Arditti, 1992). Entretanto, plântulas cultivadas por esse processo raramente sobrevivem, quando transferidas para seu habitat natural em programas de reintrodução de espécies no campo (Clements et al., 1986; Anderson, 1991).

Fungos micorrízicos de orquídeas vêm sendo isolados de seus hospedeiros naturais, visando à germinação de sementes de orquídeas in vitro, para fins de reintrodução de espécies ameaçadas de extinção em seu ambiente natural (Zettler, 1997; Zettler et al., 2000; 2001; Stewart \& Zettler, 2002; Pereira et al., 2003b), multiplicação de espécies de interesse ornamental (Zettler et al., 1999; Wang et al., 2000) e medicinal (Chang \& Chou, 2001). Entretanto, os poucos trabalhos sobre germinação de sementes de orquídeas por fungos micorrízicos têm sido voltados para espécies terrestres de ambientes temperados (Zettler \& Mclnnis, 1993; Zetller, 1997; Zelmer \& Currah, 1997; Zettler \& H ofer, 1998; Zettler et al., 2000; 2001), bem como os trabalhos sobre o cultivo simbiótico a partir de sementes de espécies epífitas são ainda bastante incipientes (Zettler et al., 1998; 1999). As queimadas, derrubadas e desbravamentos de fragmentos remanescentes da Mata Atlântica têm levado à extinção deal gumas espécies, ou tornandoas cada vez mais de difícil acesso, daí a grande dificuldade de isolar fungos micorrízicos que, durante milhares de anos, coevoluíram com seus hospedeiros naturais, considerando tais fungos de fundamental importância em futuros programas de reintrodução dessas espécies em seu habitat natural (Zettler, 1997; Pereira et al., 2003b). Além do isolamento do hospedeiro natural, fungos micorrízicos em cultura pura, previamente isolados de diferentes hospedeiros, são usualmente empregados no cultivo simbiótico da espécie de interesse, visando estudos de especificidade e sel eção de isolados que promovam o mel hor desenvolvimento dos protocórmios (Zettler \& Mclnnis, 1993; Masuhara \& Katsuya, 1994; Zetller, 1997; Zettler \& Hofer, 1998; Zettler et al., 1999; 2000; 2001; Lekshmi et al., 2000; Wang et al., 2000; Batty et al., 2001; Stewart \& Zettler, 2002). 
Oncidium flexuosum Sims é uma espécie de orquídea epífita, de ocorrência comum em fragmentos remanescentes de Mata Atlântica em al guns estados do Brasil, de interesse em programas de reintrodução de espécies de orquídeas, além de serem de interesse comercial para a horticultura.

O objetivo destetrabal ho foi avaliar a capacidade de isolados de fungos rizoctonióides, pertencentes ao banco de germoplasma de fungos micorrízicos de orquídeas do Laboratório de Associações Micorrízicas, BIOAGRO/UFV, de induzir a germinação de sementes de O. flexuosum in vitro.

\section{MATERIAL E MÉTODOS}

\section{Obtenção das sementes}

Cápsulas maduras foram coletadas de pendões florais deO. flexuosum. As sementes foram retiradas das respectivas cápsulas elevadas para secagem em dessecador com sílica gel, à temperatura ambiente. Tais cápsulas foram embaladas em papel de filtro Whatman $\mathrm{n} 01$ e armazenadas em frascos de vidro que continham sílica gel à temperatura de $4^{\circ} \mathrm{C}$ em câmara fria, no escuro, por 30 dias.

\section{I solados fúngicos}

Dez isolados (M 1 a M 10), pertencentes à col eção de fungos micorrízicos de orquídeas do Laboratório deAssociações Micorrízicas, BI OAGRO/UFV, foram utilizados para induzir a germinação das sementes de O. flexuosum (Quadro 1). Os fungos foram isolados de orquídeas epífitas e terrestres de diferentes localidades do estado de Minas Gerais (Pereira, 2001; Pereira et al., 2001; 2003a). Os isolados, originalmenteestocados em tubos deensaio que continham água destilada esterilizada, a $4 \stackrel{\circ}{\circ} \mathrm{C}$ em câmara fria, foram reativados em placas de Petri com $25 \mathrm{~mL}$ de meio ágar-aveia (Difco) e incubados em B.O.D. a $28{ }^{\circ} \mathrm{C}$ por sete dias.

\section{Desinfestação das sementes}

As sementes de O. flexuosum, colocadas dentro de seringas esterilizadas para desinfestação superficial, foram imersas em solução de hi pocl orito de $\mathrm{Na}(\mathrm{NaOCl})$ com $2 \%$ de $\mathrm{Cl}$ ativo por 5 min e enxaguadas três vezes sucessivas emágua destilada autoclavada. U ma amostra de $2 \mathrm{~mL}$ da solução final, homogeneizada e que continha sementes superficialmente desinfestadas e água destilada esterilizada, foi utilizada para contagem do número de sementes, sob microscópio estereoscópico (Olympus SZH 10).

\section{Cultivo simbiótico}

Aproximadamente, 300 sementes foram uniformemente distribuídas em papel de filtro (Wathman $\mathrm{n}^{\circ} 3$ ) com $2,3 \mathrm{~cm}$ de diâmetro, previamente esterilizado, dentro de placas de Petri quecontinham $20 \mathrm{~mL}$ de meioágar-aveia modificado (Dixon, 1987). As placas foram inocul adas com blocos de $1 \mathrm{~cm}^{3}$ de meio ágar-aveia com o micélio fúngico do isolado micorrízico, retirados das bordas das colônias resultantes do crescimento dos isolados reativados. A inoculação foi feita a uma distância de $6 \mathrm{~cm}$ do disco de papel filtro. As placas foram seladas com filme PVC e incubadas a $25^{\circ} \mathrm{C}$, no escuro, durante duas semanas. Três repetições para cada isolado foram distribuídas al eatoriamente em câmara escura. Placas que continham sementes, porém não inoculadas, serviram de controle.

A germinação foi monitorada sob microscópio estereoscópico a cada três dias, durante as duas primeiras semanas. Após esse período, as placas foram removidas do escuro e levadas para câmaras de crescimento com fotoperíodo regulado de $12 \mathrm{~h}$, com temperaturas diurnas de $28{ }^{\circ} \mathrm{C}$ e noturnas de $25^{\circ} \mathrm{C}$. Aos 50 dias de idade, os discos foram retirados

\section{Quadro 1. Código, identificação e hospedeiro original dos isolados de fungos micorrízicos utilizados no experimento}

\begin{tabular}{cll}
\hline Código do isolado & \multicolumn{1}{c}{ Identificação } & \multicolumn{1}{c}{ Hospedeiro original(1) } \\
\hline M1 & Epulorhiza epiphytica Pereira, Rollemberg et Kasuya & Polystachia concreta (J acq.) Garay \& Sweet \\
M2 & Ceratorhiza sp. & Oncidium flexuosum Sims \\
M3 & Ceratorhiza sp. & I sochillus lineares ( J acq.) R. Br \\
M4 & Ceratorhiza sp. & Maxillaria marginata (Lindl.) Fenzl \\
M5 & Epulorhiza repens (Bernard) Moore & Oeceoclades maculata (Lindl.) Lindl. \\
M6 & E. epiphytica & E pidendrum rigidum J acq. \\
M7 & Ceratorhiza sp. & Oncidium varicosum Lindl. \\
M8 & Rhizoctonia sp. & Gomesa crispa (Lindl.) Klotzsch ex Rchb. f. \\
M9 & Ceratorhiza sp. & Campylocentrum organensis (Rchb. f.) Rolfe \\
M10 & Ceratorhiza sp. & Bulbophyllum sp. \\
\hline
\end{tabular}

(1) Hospedeiro de onde os isolados fúngicos foram originalmente obtidos (Pereira, 2001; Pereira et al., 2001; 2003a). 
das placas de Petri e observados sob microscópio estereoscópico para avaliação da percentagem de germinação e desenvolvimento dos protocórmios.

\section{Avaliação da germi nação e do desenvolvimento do protocórmio}

Aos diferentes estádios de desenvolvimento dos protocórmios foram atribuídas notas de 0 a 5 , adaptadas de Zettler \& Hofer (1998), a saber: $0=$ não ocorreu germinação; 1 = embrião bem desenvol vido dentro do envol tório; 2 =rompimento do tegumento; 3 = início de desenvolvimento das radicelas; $4=$ formação da primeira folha com radicelas bem desenvol vidas e $5=$ protocórmio com $0,5 \mathrm{~cm}$ de diâmetro, com formação da segunda fol ha e primeiras raízes. O valor da percentagem de germinação e de protocórmi os nos diferentes estádios de desenvolvimento foi obtido por meio da média aritmética das três repetições de cada tratamento.

\section{Caracterização da associação micorrízica e anatomia da interação fungo-planta}

Protocórmios em diferentes estádios de desenvolvimento foram seccionados Iongitudinalmente, a mão livre, e observados em microscópio ótico (OLYMPUS BX 50), para verificar a formação deestruturas fúngicas intracelulares (pelotons) que caracterizam a associação simbiótica micorrízica em orquídeas (Smith \& Read, 1997; Zettler, 1997). Os embriões e os protocórmios foram clareados e corados com azul de tripano, segundo método proposto por Phillips \& Hayman (1970). Radicelas coradas foram também cuidadosamente montadas entre lâmina e lâmínula com lactoglicerol para observação em microscópio ótico dos sítios de infecção do fungo micorrízico.

\section{RESULTADOS E DISCUSSÃO}

\section{Cultivo simbiótico}

Aos sete dias de idade, cerca de $90 \%$ das sementes de $\mathrm{O}$. flexuosum germinaram quando inoculadas com o isolado M2 (Ceratorhiza sp.). Somente aos 30 dias de idade, observou-se a germinação das sementes induzidas por outros isolados. Na ausência do fungo micorrízico, as sementes não germinaram, demonstrando dependência da espécie de orquídea pel o fungo micorrízico. A percentagem de germinação e de protocórmios nos diferentes estádios de desenvol vimento, para cada isolado, pode ser observada no quadro 2.

Aos 50 dias de idade, protocórmios nos estádios 3, 4 e 5 foram observados somente quando inoculadas com o isol ado M2 (Figura 1C), original mente obtido do sistema radicular deO. flexuosum, indicando um possível caso de especificidadefungo-hospedeiro. Os demais isolados de Ceratorhiza, bem como os isolados de Epulorhiza e Rhizoctonia, apesar de terem provocado a germinação de sementes, desenvol veram protocórmios somente até o estádio 2 (Figura 1D). Esses resultados indicama existência de alguma barreira ou a falta de algum estímulo nessas combinações fungo-planta, conforme foi também evidenciado em outros trabalhos de germinação simbiótica (Anderson, 1991; Zettler \&

Quadro 2. Percentagem de germinação em diferentes estádios de desenvolvimento dos protocórmi os de Oncidi um flexuosum, $\mathbf{5 0}$ dias após inoculação das sementes por dez isolados de fungos micorrízicos

\begin{tabular}{|c|c|c|c|c|c|c|}
\hline \multirow{2}{*}{ Código do isolado } & \multicolumn{6}{|c|}{ E stádio de desenvolvimento } \\
\hline & $\mathbf{0}$ & 1 & 2 & 3 & 4 & 5 \\
\hline & \multicolumn{6}{|c|}{ - Germinação, \% - } \\
\hline M1 & 5 & 12 & 83 & 0 & 0 & 0 \\
\hline M2 & 2 & 31 & 22 & 15 & 16 & 14 \\
\hline M3 & 88 & 10 & 2 & 0 & 0 & 0 \\
\hline M4 & 85 & 10 & 5 & 0 & 0 & 0 \\
\hline M5 & 5 & 15 & 80 & 0 & 0 & 0 \\
\hline M6 & 3 & 11 & 86 & 0 & 0 & 0 \\
\hline M7 & 97 & 3 & 0 & 0 & 0 & 0 \\
\hline M8 & 83 & 12 & 5 & 0 & 0 & 0 \\
\hline M9 & 85 & 15 & 0 & 0 & 0 & 0 \\
\hline M10 & 87 & 10 & 3 & 0 & 0 & 0 \\
\hline Controle & 100 & 0 & 0 & 0 & 0 & 0 \\
\hline
\end{tabular}


Mdnnis, 1992; Zelmer \& Currah, 1997; Zettler \& Hofer, 1998; Zettler et al., 1999).

A especificidade da associação micorrízica em orquídeas é ainda fonte de controvérsia, visto que, enquanto alguns trabal hos demonstram a existência de especificidade entre fungo e planta (Warcup, 1971; 1973; 1981), outros demonstram a baixa ou, até mesmo, a inexistência de especificidade (Hadley, 1970; Deutsch, 2001; Stewart \& Zettler, 2002). Além da dificul dade de identificação das espécies de fungos rizoctonióides comumente isolados de raízes micorrizadas de orquídeas, a aval iação de trabal hos sobre especificidade é ainda dificultada pela variabilidade de métodos de isolamento empregados, pelos diferentes estádios de desenvolvimento dos hospedeiros estudados e pela não-correspondência entre experimentos de germinação de sementes em condições naturais e in vitro (Andersen \& Rasmussen, 1996).

Analisando o cultivo simbiótico de Platanthera clavellata, Zettler \& Hofer (1998) observaram que um isolado de E pulorhiza inquilina, originalmente obtido do sistema radicular de P. clavellata, promoveu o desenvolvimento significativamente superior de protocórmios em relação a outros isolados de $\mathrm{E}$. inquilina, originalmente obtidos do sistema radicular de Platanthera ciliares, Platanthera cristata e Platanthera integrilabia. O mesmo foi observado neste experimento em relação ao desenvolvimento de protocórmios de $\mathrm{O}$. fl exuosum, comparando-se os resultados obti dos pelo isolado M2, originalmente isolado de O. flexuosum, e o isolado M7, originalmente isolado de $\mathrm{O}$. vari cosum. Apesar de terem sido os isolados obtidos do sistema radicular de hospedeiros pertencentes ao mesmo gênero, o isolado M2 promoveu o desenvolvimento de protocórmios até o estádio 5 , enquanto o isolado $M 7$ promoveu o desenvolvimento de protocórmi os somente atéo estádio 2 (Quadro 1). Entretanto, resultados contraditórios são observados em experimentos em que isolados, originalmente obtidos do sistema radicular de seus hospedeiros naturais, promovem menor desenvolvimento de protocórmios em relação a isolados originalmente obtidos de outros hospedeiros não relacionados (Zettler et al., 1999), ou mesmo pertencentes ao mesmo gênero (Zettler et al., 2000).

Fungos rizoctonióides fitopatogênicos podem formar associações simbióticas micorrízicas com membros da família Orchidaceae (Masuhara \& Katsuya, 1994), assim como fungos rizoctonióides em associação simbiótica, sob determinadas condições, podem estabelecer associação fitopatogênica (Zelmer et al., 1996; Wang et al., 2000). Os isolados M 3 e M 4 de Ceratorhiza, apesar de levarem à germinação de sementes, estabeleceram associação fitopatogênica com os protocórmios de segundo estádio de desenvolvimento. Esses isol ados, M3 e M4, foram originalmente obtidos, respectivamente, de I. lineares e $\mathrm{M}$. marginata, sendo possível que algum mecanismo molecular essencial ao estabelecimento da associação simbiótica entre a planta e o fungo não tenha sido expresso ou reconhecido.

\section{Caracterização da associação micorrízica e anatomia da interação fungo-planta}

Todos os isolados foram capazes de levar à germinação das sementes de 0 . flexuosum, porém o isolado M2 foi o único capaz de promover o desenvolvimento completo dos protocórmios (Figura $1 C$ ). Inicialmente, as hifas penetram por poros localizados nas extremidades das sementes, infectando as células suspensoras. Posteriormente, as hifas penetram pela parede celular das células do córtex, localizadas adjacentes às células suspensoras, ramificando-se entre a parede celular e a membrana citoplasmática. A pós a ramificação, as hifas enovelam-se, dando origem aos pelotons (Figura $1 E$ ), estruturas que caracterizam a associação micorrízica orquidóide. Formados os pelotons, o embrião desenvolve-se (Figura $1 F$ ) por meio dos produtos advindos da digestão enzimática do fungo simbionte (Figura 1G), dando origem aos protocórmios.

Somente para o isolado M2 observou-se a capacidade de infectar radicelas de 0 . flexuosum. Dois padrões de infecção das radicel as puderam ser observados: um interno, por mei o dehifas localizadas no interior do protocórmio, e outro externo, por meio de hifas localizadas no substrato de crescimento. H ifas originárias de pel otons local izados nas células mais externas do córtex infectam as radicelas por suas células basais. Essas hifas penetram pela parede da radicela jovem, colonizando toda a sua extensão, até à extremidade apical, atravessando novamente a parede celular, entrando novamente em contato com o meio de cultura (Figura $1 \mathrm{H})$. J á hifas originadas diretamente do micélio em crescimento podem também infectar as radicelas, lateral mente, penetrando através da parede celular (Figura 1l). Antes da formação das raízes verdadeiras, a col onização das radicelas a partir das células mais externas do córtex al cançam novamente o substrato de crescimento e talvez seja o principal fator responsável pela estabilidade do protocórmio de orquídeas epífitas na natureza.

Por outrolado, a col onização a partir do substrato de crescimento alcança o interior das radicelas e atua, possivel mente, na estabilidade do protocórmio em condições naturais, além de ser um indicativo "anatômico da possibilidade de micorrização" de protocórmios cultivados assimbioticamente in vitro, em condicões de laboratório. Radicelas infectadas, em estádio mais avançado de desenvolvimento, apresentavam-se bastante col onizadas por cordões de hifas, permitindo a visualização de cerca de 5-7 hifas individualizadas por cordão, as quais se 

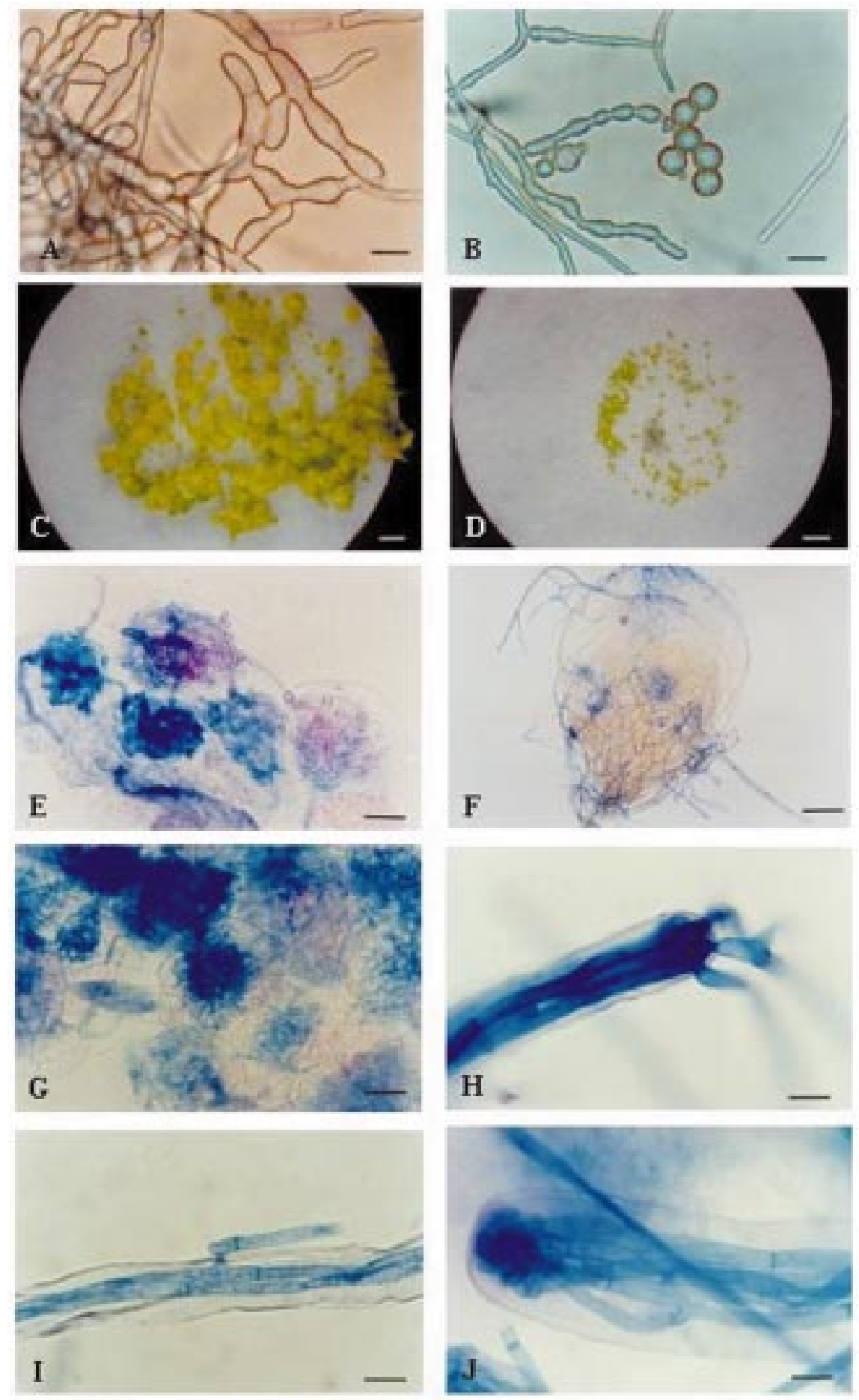

Figura 1. (A) Células monilióides de Ceratorhiza sp., isolado M2 e (B) de E pulorhiza epi phytica, isolado M1; (C) Protocórmios de Oncidium flexuosum formados em cultivo si mbiótico com o isolado M2 e (D) com o isolado M1; (E ) Presença de pel otons intactos nas células do córtex do embrião de 0 . flexuosum em cultivo simbiótico com o isolado M2 de Ceratorhiza sp. corado com azul de tripano 0,05\%; (F) E mbrião de O. flexuosum em desenvolvimento após inoculação com o isolado M2; (G) Presença de pelotons intactos e degradados nas células do córtex do protocórmio de 0 . flexuosum em cultivo simbiótico com o isolado M2; (H) H ifas vegetativas do isolado M2 saindo pela extremidade apical da radicela de 0 . flexuosum; (I) Infecção lateral e colonização da radicela de 0 . flexuosum pelo isolado M2 e ( ) Radicela em estádio mais avançado de desenvolvimento, colonizada por diversas hifas, mostrando o enovelamento na região da extremidade apical da radicela. Barras: (A) e (B) $=20 \mu \mathrm{m}$; (C)

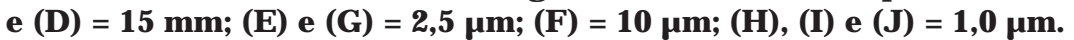


enovelavam na extremidade apical da radicela (Figura 1J ), provavelmente dando origem aos pelotons das células do córtex da raiz primária. Padrões similares de infecção da semente, desenvolvimento do embrião e colonização da radicela são relatados para Pterostylis spp. em associação com Ceratobasidium spp. na Austrália (Clements, 1988).

\section{CONCLUSÕES}

1. O sucesso na germinação das sementes, assim como o estabel ecimento de protocórmi os in vitro por mei o do método cultivo simbiótico, utilizando fungos micorrízicos em cultura pura, é relatado, pela primeira vez, para O. flexuosum.

2. Oncidium flexuosum parece estabelecer associação específica com seu simbionte mi cor rízico, pelo menos no que diz respeito à germinação simbiótica de sementes e estabel ecimento do protocórmio in vitro.

3. Fungos rizoctonióides podem estabelecer não só associação mi corrízica em diferentes níveis, mas também associação fitopatogênica, em al guns casos.

4. Isolados que promovam o desenvolvimento adequado devem ser selecionados a depender da espécie de orquídea a ser propagada em cultivo simbiótico.

\section{AGRADE CIME NTOS}

Ao Instituto Estadual de Florestas (IEF) pela concessão de registro para coleta de orquídeas e sementes em áreas de conservação biológica do estado de Minas Gerais. Este trabalho faz parte integrante do estudo da biodiversidade de fungos micorrízicos associados ao sistema radicular de orquídeas brasileiras, financiado pela Fundação de Amparo à Pesquisa do estado de Minas Gerais (FAPEMIG), registro 708/02. Ao CNPq, pela concessão de bolsas de pós-graduação, de produtividade e de iniciação científica dos autores. À Sociedade Brasileira deOrquidófilos (OrquidaRio) e ao Ph.D. Larry Peterson, University of Guelph (Canadá), pelo constante apoio e incentivo.

\section{LITE RATURA CITADA}

ANDERSEN, T.F. \& RASMUSSEN, H.N. The mycorrhizal species of Rhizoctonia. In: SNEH, B.; J ABAJ I-HARE, S.; NEATE, S. \& DIJ ST, G., eds. Rhizoctonia species: taxonomy, molecular biology, ecology, pathology, and disease control. Dordrecht, Kluwer Academic Publishers, 1996. p.379-390.
ANDERSON, A.B. Symbiotic and asymbiotic germination and growth of Spitanthes magnicamporum (Orchidaceae). Lindleyana, 6:183-186, 1991.

ARDITTI, J. Fundamentals of orchid biology. 2.ed. New York, J ohn Wiley \& Sons, 1992. 691p.

BATTY, A.L.; DIXON, K.W.; BRUNDRETT, M. \& SIVASITHAMPARAM, K. Long-term storage of mycorrhizal fungi and seed as a tool for the conservation of endangered Western Australian terrestrial orchids. Aust. J . Bot., 49:619-628, 2001.

CHANG, D.C.N. \& CHOU, L.C. Seed germination of Haemaria discolor var. dawsoniana and the use of mycorrhizae. Symbiosis, 30:29-40, 2001.

CLEMENTS, M.A.; MUIR, H. \& CRIBB, P.J . A preliminary report on the symbiotic germination of European terrestrial orchids. Kew Bull., 41:437-445, 1986.

CLEMENTS, M.A. Orchid mycorrhizal associations. Lindleyana, 3:73-86, 1988.

DEUTSCH, G. In vitro-Annzucht von Nitritella (Orchidaceae Orchideae) aus Samen, mit Hilfe von symbiotischen Pilzen. Phyton., 41:111-128, 2001.

DIXON, K. Raising terrestrial orchids from seed. In: HARRIS, W.K., ed. Modern orchid growing for pleasure and profit. Adelaide, Orchid Club of South Australia, 1987. p.47-100.

HADLEY, G. Non-specificity of symbiotic infection in orchid mycorrhiza. New Phytol., 69:1015-1023, 1970.

HARVAIS, G. \& HADLEY, G. The relation between host and endophyte in orchid mycorrhiza. New Phytol., 66:205-215, 1967.

LEAKE, J . The biology of myco-heterotrophic ('saprophytic') plants. New Phytol., 127:171-216, 1994.

LEKSHMI, S.N.; TAN, T.K. \& LOH, C.S. Effects of mycorrhizal infection on different stages of tissue-cultured Dendrobium sonia. In: INTERNATIONAL SYMPOSIUM ON RHIZOCTONIA, 3., Taichung, 2000. Anais. Taiwan, International Society of Plant Pathology (Rhizoctonia Committee), 2000

MASUHARA, G. \& KATSUYA, K. In situ and in vitro specificity between Rhizoctonia spp. and Spiranthes sinensis (Persoon) Ames. var. amoema (M. Bieberstein) Hara (Orchidaceae). New Phytol., 127:711-718, 1994.

MCKENDRICK, S.L.; LEAKE, J .R.; TAYLOR, D.L. \& READ, D.J . Symbiotic germination and development of mycoheterotrophic plants in nature: ontogeny of Corallorhiza trifida and characterization of its mycorrhizal fungi. New Phytol., 145:523-537, 2000.

PEREIRA, O.L. Caracterização morfológica e molecular de fungos micorrízicos de sete espécies de orquídeas neotropicais. Viçosa, U niversidade F ederal de Viçosa, 2001. 48p. (Tese de Mestrado)

PEREIRA，O.L.; ROLLEMBERG, C.L.; BORGES, A.C.; MATSUOKA, K. \& KASUYA, M.C.M. Epulorhiza epiphytica sp. nov. isolated from mycorrhizal roots of epiphytic orchids in Brazil. Mycoscience, 44:153-155, $2003 a$. 
PEREIRA, O.L.; ROLLEMBERG, C.L. \& KASUYA, M.C.M. Association des mycorhizies dans les orchidees perspectives d'utilisation dans les programmes de propagation symbiotique. Orchidees, 55:24-27, 2003b.

PEREIRA, O.L.; ROLLEMBERG, C.L.; PEIXOTO, H.T.M.; ARAÚJ O, E.F.; BORGES, A.C. \& KASUYA, M.C.M. Epulorhiza repens: a orchid mycorrhizal fungus of Oeceoclades maculata. In: CONGRESSO BRASI LEIRO DE MICROBIOLOGIA, 21., Foz do I guaçu, 2001. Anais. Foz do I guaçu, Sociedade Brasileira de Microbiologia, 2001. p.259.

PETERSON, R. L.; UETAKE, Y \& ZELMER, C. Fungal simbiosis with orchid protocorms. Symbiosis, 25:29-55, 1998.

PHILLIPS, J .M. \& HAYMAN, D.S. I mproved procedure for clearing roots and staining parasitic and vesiculararbuscular mycorrhizal fungi for rapid assessment of infection. Trans. Br. Mycol. Soc., 55:158-161, 1970.

READ, D.J .; DUCKETT, J .G.; FRANCIS, R.; LIGRONE, R. \& RUSSELL, A. Symbiotic fungal associations in 'lower' land plants. Phil. Trans. R. Soc., 355:815-831, 2000.

SMITH, S.E. \& READ, D.J . Mycorrhizal symbiosis 2.ed. San Diego, Academic Press, 1997. 605p.

STEWART, S.L. \& ZETTLER, L.W. Symbiotic germination of three semi-aquatic rein orchids (Habenaria repens, $H$. quinquiseta, H. macroceratilis) from Florida. Aquatic Bot., 72:25-35, 2002.

TAYLOR, D.L.; BRUNS, T.D.; LEAKE, J .R. \& READ, D.J . Mycorrhizal specificity and function in myco-heterotrophic plants. E col. Studies, 157:375-413, 2002.

WANG, C.L.; CHU, J .N.; CHEN, C.Y.\& CHAO, Y.C. Influence of orchid mycorrhizal fungi Rhizoctonia spp. on the growth of Oncidium Goldiana X Onc. Guiena Gold seedlings. In: INTERNATIONAL SYMPOSIUM ON RHIZOCTONIA, 3., Taichung, 2000. Anais. Taiwan, International Society of Plant Pathology (Rhizoctonia Committee), 2000.

WARCUP, J.H. Symbiotic germination of some Australian terrestrial orchids. New Phytol., 72:387-392, 1973.
WARCUP, J.H. The mycorrhizal relationships of Australian orchids. New Phytol., 87:371-381, 1981.

WARCUP, J.H. \& TALBOT, P.H.B. Perfect states of rhizoctonias associated with orchids. II. New Phytol., 70:35-40, 1971.

ZELMER, C.D.; CUTHBERTSON, L. \& CURRAH, R.S. Fungi associated with terrestrial orchid mycorrhizas, seeds and protocorms. Mycoscience, 37:439-448, 1996.

ZELMER, C.D. \& CURRAH, R.S. Symbiotic germination of Spiranthes lacera (Orchidaceae) with a naturally occurring endophyte. Lindleyana, 12:142-148, 1997.

ZETTLER, L.W. Orchid-fungal symbiosis and its value in conservation. Mcl vainea, 13:40-45, 1997.

ZETTLER, L.W.; BURKHEAD, J.C. \& MARSHALL, J .A. Use of a mycorrhizal fungus from Epidendrum conopseum to germinate seed of Encyclia tampensis in vitro. Lindleyana, 14:102-105, 1999.

ZETTLER, L.W.; DELANEY, T.W. \& SUNLEY, J. Seed propagation of the epiphytic Green-fly orchid, E pidendrum conopseum R. Brown, using its endophytic fungus. Sel bayana, 19:249-253, 1998.

ZETTLER, L.W. \& HOFER, C.J . Propagation of the little clubspur orchid (Platanthera clavellata) by symbiotic seed germination and its ecological implications. Environ. Exp. Bot., 39:189-195, 1998.

ZETTLER, L.W. \& MCINNIS, T.M. Symbiotic germination and devel opment of Spiranthes cernua and Goodyera pubescens (Orchidaceae: Spiranthoideae). Lindleyana, 8:155-162, 1993.

ZETTLER, L.W.; STEWART, S.L.; BOWLES, M.L. \& J ACOBS, K.A. Mycorrhizal fungi and cold-assisted symbiotic germination of the federally threatened eastern praire fringed orchid, Platanthera leucophaea (Nuttall) Lindley. Am. Midl. Nat., 145:168-175, 2001.

ZETTLER, L.W.; SUNLEY, J .A. \& DELANEY, T.W. Symbiotic seed germination of an orchid in decline (Platanthera integra) from the Green Swamp, North Carolina. Castanea, 65:207-212, 2000. 